7?

columns side Western medicine. This certainly does not differ in patients with psychiatric illnesses. Herbal remedies are sought for symptoms of depression, phobias and other psychiatric disorders. Advertisements that offer a herbal remedy for any sexual problem are abundant in the newspapers. Memory boosters are also much sought after.

Most people obtain these herbal remedies from small shops in villages and towns. Some obtain them from the village 'medicine man'. Herbal remedies are also sold in larger shops with minimum regard to the legislation in place. A survey carried out in the out-patient psychiatry clinic at the North Colombo teaching hospital found that $25.5 \%$ of psychiatric patients had used herbal medication at some point. A longer duration of psychiatric illness was related to the greater use of herbal medication. A majority of patients who used herbal remedies were not aware that there can be harmful interactions with other medications. This can have disastrous consequences when herbal medication is used in a complementary role.

Use of herbal remedies as alternative medication may also contribute to a delay in seeking treatment. Patients may prefer to use herbal remedies, which are less stigmatising than psychotropic medication. This may result in a delay in treatment which may have negative effects on prognosis.

*K. A. L. A. Kuruppuarachchi Professor of Psychiatry, University of Kelaniya, Faculty of Medicine, Ragama, Sri Lanka, email: lalithkuruppa@ lycos.com, L.T. Wijeratne Lecturer in Psychiatry, University of Kelaniya, Faculty of Medicine, Ragama, Sri Lanka

doi: $10.1192 / p b .31 .4 .153 b$

\section{Smoking has no place in psychiatric hospitals}

O'Gara \& Mclvor (Psychiatric Bulletin, July 2006, 30, 241-242) address the issue of smoke-free legislation and mental health units and endorse the view that smoking cessation should be encouraged in psychiatric hospital settings. The concern remains that some psychiatric units will be exempt from the smoking ban. This can only further alienate psychiatry from medicine and increase stigma against psychiatric patients and services. Admission of smokers with mental illness to smoke-free psychiatric units may lead to behavioural deterioration, but some evidence refutes this argument. The implementation of a smoking ban, establishing a smoke-free psychiatric service and abolishing tobacco products, created minor management difficulties on a locked psychiatric unit (Ryabik et al, 1994). The effects of prohibiting cigarette smoking on the behaviour of patients on a 25-bed psychiatric in-patient unit were assessed immediately after implementation of a smoking ban and 2 years later. No behavioural disruptions were observed after the ban, and discharges against medical advice did not increase immediately after the restriction on smoking or 2 years later (Velasco et al, 1996).

Signs and symptoms of nicotine withdrawal and alterations in psychopathology were evaluated among psychiatric patients with acute illness admitted to a hospital with a smoking ban (Smith et al, 1999). Despite patients' reports of feeling distressed and of experiencing nicotine withdrawal symptoms, abrupt cessation of smoking did not affect psychopathological symptoms during admission (Smith et al, 1999).

The above evidence shows that smoking has no place in psychiatric hospitals, and that a smoking ban can only improve the well-being of patients, staff and visitors

RYABIK, B. M., LIPPMAN, S. B. \& MOUNT, R. (1994) mplementation of a smoking ban on a locked psychiatric unit. General Hospital Psychiatry, 16, 200-204.

SMITH, C. M., PRISTACH, C. A. \& CARTAGENA, M. (1999) Obligation cessation of smoking by psychiatric inpatients. Psychiatric Services, 50, 91-94.

VELASCO, J., EELLS, T. D., ANDERSON, R., et al (1996) A two year follow up on the effects of smoking ban in an inpatient psychiatric service. Psychiatric Services, 47, 869-871

Faouzi Dib Alam Specialist Registrar, Royal Preston Hospital, Preston PR2 9HT, email: docftalam@aol.com

doi: $10.1192 / p b .31 .4 .154$

\section{Access to articles for hospital journal clubs}

Evidence-based critical appraisal of articles in journal clubs forms an essential part of psychiatric training. The College emphasises the importance of journal clubs as part of the postgraduate teaching programme (Royal College of Psychiatrists, 2003) and a journal club presentation will be one of the workplace-based assessments undertaken by trainees to demonstrate competencies in the new curriculum (Royal College of Psychiatrists, 2006).

However, since the loss of the National Health Service licence regarding copyright privilege it has become increasingly difficult to organise journal clubs. Previously, once a paper was identified, it could be photocopied and sent out in advance or handed out at the session. Now each individual attending must be sent details of the paper, and they must download and print their own copy. This involves excessive time and also increases cost (as printing is more expensive than photo copying). It also means that many trainees fail to have a copy of the paper for discussion, either because of lack of computer access, lack of time or perhaps through laziness. This certainly does not facilitate good-quality teaching and learning.

We wonder if other teaching programmes have had similar experiences and it they have found a more convenient way to organise access to journal articles. One way forward would be for the College to authorise the reproduction of its own publications for members organising journal clubs, allowing photocopying of articles from several peerreviewed, hopefully high-quality journals.

ROYAL COLLEGE OF PSYCHIATRISTS (2003) Basic Specialist Training Handbook. Royal College of Psychiatrists. http://www.rcpsych.ac.uk/PDF/ bst.pdf

ROYAL COLLEGE OF PSYCHIATRISTS (2006)

Curriculum Pilot Pack. Royal College of Psychiatrists. http://www.rcpsych.ac.uk/training/ curriculumpilotpack.aspx

Jessica Beard Specialist Registrar, Northern Deanery Higher Specialist Training Scheme in General and Old Age Psychiatry, * Peter L. Cornwall Consultant Psychiatrist, Tees, Esk and Wear Valleys NHS Trust, St Luke's Hospital, MiddlesbroughTS4 3AF, email: lenny.cornwall@tney.northy.nhs.uk

doi: $10.1192 / \mathrm{pb} .31 .4 .154 \mathrm{a}$

\section{Parrots as therapy for psychiatric patients}

I would agree with Pease \& Brown (Psychiatric Bulletin, December 2006, 30 463) that parrots are probably not suitable for health centres, not because of confidentiality problems but because they can be noisy and it is unfair to keep them constantly caged. When parrots breach confidentiality it is with phrases they have heard repeatedly and with emotion. There are cases of parrots squawking lovers' names and leading to the break up of both human and parrot relationships (for example, the sad story of Ziggy in Daily Telegraph, 17 January 2006).

I have kept pet parrots for 20 years and can recommend them for the house bound, the lonely and patients with depression, especially middle-aged women suffering from the 'empty nest syndrome'. They can be extremely loyal and loving, providing companionship and better quality entertainment than television. They are highly intelligent, social animals, and African Greys can learn to use words in a meaningful way. They do, however, have complex needs and some species, such as cockatoos, should be avoided as they become neurotic if their emotional demands are not met. Amazons (the green ones) are a good bet. Their longevity can also be a problem (for example when elderly owners require nursing home care). It is important to purchase an English-bred bird, preferably one that has been hand-reared. I would advise prospective owners to contact The Parrot Society UK (http://www. theparrotsocietyuk.org) who produce a 
number of thoughtful publications on the care and needs of these birds.

Camilla Haw Consultant Psychiatrist, Isham House, St Andrew's Hospital, Billing Road, Northampton NN1 5DG, email: chaw@standrew.co.uk

doi: $10.1192 / p b .31 .4 .154 b$

\section{Forensic telepsychiatry}

We read the article by Jones et al on setting up a telepsychiatry service (Psychiatric Bulletin, December 2006, 30, 464-467) with interest and optimism, having developed the first forensic telepsychiatry service in Nottinghamshire in 2005 (Saleem \& Stankard, 2006). To date, we have undertaken 30 forensic assessments, 4 of which have resulted in hospital admissions. Assessments were primarily undertaken using existing videolink facilities within local magistrates courts and HM prisons. Our experiences support the opinion that this saves time, cost (Zollo et al, 1999) and improves access to psychiatric services (Zaylor et al, 2000)

However, although Jones et al describe the development of services, they do not state whether they have assessed patients themselves using videoconferencing facilities. If they have, it would be useful to establish links between telepsychiatric services within the UK, forensic or otherwise.

At the College's invitation, we are conducting a workshop on this subject in Prague, at the Annual Meeting of the Forensic Faculty in February 2007. We have also developed a forensic telepsychiatric steering group, with a research sub-committee, in Nottingham. We are coordinating several research projects which are exploring the use of teleconferencing facilities within forensic psychiatry. We would welcome any additional views and opinions on expanding this work.

It is crucial for services across the UK to share experiences and promote practices. The promotion of telepsychiatry has the potential to change current practice positively. This is particularly important if we are to succeed in delivering timely, easily accessible and clinically sound psychiatric services, with the additional spotlight on cost-efficiency with respect to health service delivery.

SALEEM, Y. \& STANKARD, P. (2006) I'm only at the end of a videolink. BMJ Career Focus, 333, 223.

ZAYLOR, C., WHITTEN, P. \& KINGSLEY, C. (2000) Telemedicine services to a county jail. Journal of Telemedicine and Telecare, 6, 93-95.

ZOLLO, S., KIENZLE, M., LOEFFELHOLZ, P., et al (1999) Telemedicine to IOWA's correctional facilities: initial clinical experience and assessment of program costs. Telemedicine Journal, 5, 291-301.

*Paul Stankard Specialist Registrar in Forensic Psychiatry, Nottinghamshire Healthcare NHS Trust, Wells Road Centre, Nottingham NG3 3AA, email: pcstankard@doctors.org.uk, Saleem Younus Consultant Forensic Psychiatrist, Nottinghamshire Healthcare NHS Trust, Wells Road Centre, Nottingham NG3 3AA

doi: 10.1192/pb.31.4.155

\section{Mental healthcare for psychiatrists}

We read the article by White et al (Psychiatric Bulletin, October 2006, 30 382-384) with great interest, as we have conducted a similar postal survey of 1640 general practitioners and psychiatrists in Devon and Cornwall regarding depression and stigma. We also achieved a high response rate $(75 \%)$, indicating the importance of this issue to doctors. When we asked about sources of help respondents would turn to if they were experiencing excessive stress, more reported that they would seek help from family and friends (95\%) and from colleagues (65\%). Our slightly different findings might be because we asked about 'stress' rather than 'mental illness', but the overall trends are similar.

The barriers to disclosing mental illness reported by White et al are supported by our findings. However, we found that barriers to seeking help very often included concerns about letting colleagues down and confidentiality, with concern about career progression cited by only $16 \%$ (although women were twice as concerned about this as men).

White et al found that $20 \%$ of psychiatrists admit to self-prescribing for mental illness, but in our study the rate was only $7 \%$. The fact that our respondents were more willing to disclose stress to colleagues and reported less selfprescribing perhaps reflects a more open culture in Devon and Cornwall since the introduction of an effective occupational health service.

Overall, our study in the South-West confirms the findings of White et al in the West Midlands. Both studies address the poorly researched but important area of doctors' attitudes towards mental illness and we agree with the recommendations of White et al. There is still a long way to go in terms of educating doctors about looking after and improving their own mental health and in reducing stigma within the medical profession.

${ }^{*}$ Alison Lee Specialist Registrar in Child and Adolescent Psychiatry, Torbay Hospital, South Devon HealthcareTrust, Torquay, TQ2 7BA, email: alisonjanelee@yahoo.com,Elizabeth Adams Specialist Registrar in Substance Misuse, Cornwal PartnershipTrust, RupertWhite Consultant Psychiatrist in Substance Misuse, Cornwall PartnershipTrust

doi: $10.1192 / p b .31 .4 .155 a$

\section{the college}

\section{The Royal College of Psychiatrists' Winter Business Meeting 2007}

The Winter Business Meeting was held at the Royal College of Psychiatrists on 23 January 2007. There were 27 members of the College present.

\section{Minutes}

The minutes of the Winter Business Meeting held at the Royal College of Psychiatrists on 24 January 2006 were approved as a correct record.

\section{Obituary}

The obituary list of members and associates who had died since the
Annual General Meeting in 2006 was received.

\section{Election of Honorary Fellows}

The following were elected to the Honorary Fellowship for 2007:

Lord Denis Victor Carter

(to be awarded posthumously) Professor Anthony Ward Clare, FRCPsych

The Rt Hon The Baroness Hale

of Richmond, DBE, PC

Dr Sheila Mann, FRCPsych

Professor Bruce Singh,

MBBS, PhD, FRACP, FRANZCP.

doi: 10.1192/pb.bp.107.014894

\section{Annual elections - Honorary Officers \\ Notice to Members and Fellows}

Fellows and Members of the College are reminded of their rights in connection with the forthcoming elections for the offices of Dean, Registrar and Treasurer.

All Honorary Officers are eligible for re-election.

The nominating meeting of the Central Executive Committee will be held on 20 April 2007 and the last date for receiving nominations will be 19 May 2007.

The relevant Bye-Laws and Regulations are printed below. 